\title{
Creative design software: Challenges and opportunities to the graphic designer in Zimbabwe
}

\begin{abstract}
The study sought to investigate the nature of issues facing the graphic designers with regards to software usage and upgrades. Technology has changed the way graphic designers do their job and this has brought some challenges and opportunities to the creative design industry in Zimbabwe. In depth interviews were carried with graphic designers currently in practice and also an open ended questionnaire was used to solicit for views from the designer perspective. From the findings it was concluded that younger designers are enrolling for the graphic design qualification in institutions of higher learning across the country. Most designers highlighted that they prefer using Adobe suite as a software package of choice even though they do not acquire the official proprietary software license. To a larger extent the graphic designers make a choice on software to buy depending with their hardware capabilities.
\end{abstract}

\section{KEY WORDS}

graphic designer, design, software, technology, crowdsourcing

\author{
Walter Chipambwa (D), \\ Takunda Chimanga (1)
}

Chinhoyi University of Technology, School of Art and Design, Chinhoyi, Zimbabwe

\author{
Corresponding author: \\ Walter Chipambwa \\ e-mail: \\ wcwalter01@gmail.com
}

\section{Introduction}

The computer is one of the greatest technological and scientific inventions of the last century. Computers have changed the way we work, influencing how we communicate, organise, store and present information (Swedin \& Ferro, 2005). The design industry is one of the sectors that have seen a complete shift in doing business due to the use of computers. Historically, designers relied on outside professionals, such as typesetters and printers, to provide the technical aspects of their trade. All the designer had to do was create the concept, seek approval from the client, and assemble the finished art to produce the printed piece (Thornton, 1996). Once the type size and style were specified for the typesetter, the resulting proofs were glued to a board with all art and design elements for the final production. This made the relationship between designers, typesetters, paper companies, and printers symbiotic. The introduction of graphic designing software such as Publisher and PageMaker in the mid-1980s, and later on Quark Xpress in 1987 , brought some changes to graphic designing as tech- nology improved. According to Perez (2010), new graphic design software allows us to skip the old ways of doing graphic design, unlike the old techniques where graphic designers could use same materials on painting to come up with an artwork. It was difficult for the graphic designers to do their work in time and also there was much labor compared to computer designing, where a design can be made in a quarter of the time it would normally take using traditional methods (Thornton, 1996). These traditional platforms are marked by painting, with the colours on paper or canvas, as well as the process requiring the designer to rely on the mind to generate ideas rather than using features of software to come up with a design of high creativity and flair. The introduction of software brought a huge impact on the field of graphic design, though graphic designing was more appreciated before the computer design software (Burgess, 2010). Whilst there might be free and open source software (FOSS), the major challenge they present to a designer is that they lack some key features important to a designer, like aesthetic feel and smoothness as compared to proprietary software. 
CorelDraw and Adobe suite are the most preferred amongst graphic designers. One problem, though, is that whilst they are all graphic design software, when it comes to compatibility the designers always finds challenges in switching. The decision on software to use and version to buy is not always an easy one for example the CorelDraw graphic suite 2017 costs not less than US\$500. For a software package to be useful to a graphic designer, it should have the three main elements that include,

1. Drawing program (both for vector and raster)

2. Image editing program

3. Layout program.

Whilst new software versions are being developed, it is not always the case that the designers can access these latest versions. One can cite many other reasons for failure to upgrade like lack of funds to pay for the license and hardware compatibility issues. As such, graphic designers are not spared this crisis in Zimbabwe. With the ubiquitous growth of the internet and globalization effects in the design industry, one can now post their design problem on the internet and get someone in another country to design for them. This puts the local designers in a fierce competing battle as designers world over can fight for the same job.

\section{Statement of the problem}

Given the need to upgrade and purchase new hardware and software, graphic designers in Zimbabwe are faced with a challenge of how they can efficiently embrace these technological advancements in an effort to keep abreast with industry changes. This research sought to explore how the graphic designers are using the various versions of software and how these have impacted on their ability to deliver a satisfactory product to the client.

\section{Study objectives}

- To assess the software problems that hinder the graphic design industry

- To gain knowledge about the usage of modern design software

- To identify the influence of software in design industry

\section{Literature review}

In the design industry, everyone is trying to outdo somebody else and this can only be achieved through usage of the appropriate tools for design in an effort to attract the client. This is also partly because technologies for graphic design are so advanced now, making it possible to generate complicated 3D images in real time.

\section{History of graphic design}

The history of graphic design goes back to drawings that are found in cave walls of some historic monuments around the world and decorations on ceramic wares (Mork, 1994). The professional label "graphic designer" gained popularity in the early $20^{\text {th }}$ century within the field of creative arts as it was used both in book design and general print design simultaneously. As the 1900s progressed, the field of graphic design started gaining popularity as new media houses opened shop, whilst the print and packaging industry also flourished. The demand for media content grew, and so did the demand for books, magazines and newspapers, thereby making the position of graphic designers popular. According to Armitage (2012), the first graphic design school was Bauhaus, founded in 1919 and located in Germany. The establishment of the Bauhaus school made graphic design to become recognizably modern. Bauhaus sought for the combining of art with technology and seeking the common roots of both fine and applied arts, driven by the objective to solve problems of visual design created by industrialisation (Meggs, 1998). Although computers started getting into the world of graphic design round the 1960s, they only became the standard for graphic designers in the 1980s (Armitage, 2012).

\section{Technological advancements in Graphic Design}

Due to recent developments of technology like the internet, the growing reliance on computers and smart phones, and a visually dominant culture, graphic design has become impossible to avoid because it is now seen as a way of communication. The introduction of steam-powered printing machines and mechanized typesetting in the $19^{\text {th }}$ century triggered the creation of machines for designing as people became less dependent on hiring manual labour and this encouraged graphic artists to be more directly involved in content production and design. The Second World War witnessed the earliest stages of modern digital computing before the computer gradually became an important digital tool in the graphic design industry. The development of digital computers, was as a result of efforts to store virtual data in a man-made machine (Gere, 2008). As a form of communication, graphic design has become more simple and efficient in its use with the introduction of software in the field. Today local individuals and small businesses can purchase graphic design software and make their own designs. This could not be done without the assistance of advanced computer technology (Thornton, 1996). New possibilities were formed in the industry of graphic design. For example, with Adobe Photoshop, Illustrator and CorelDraw, one can scan photographs onto the computer, manipulate them, and incorporate the photo into an exclusive graphic design template. Thornton (1996) also reports that that before computer software was used in graphic design; there was a notable limit in 
quality and also number of graphic artworks produced in the design industry. Graphic design has come a long way from its days on letterpress, with designers now competently able to also create websites using the Adobe web creation tool for designers like Muse Beta (Evans, 2014).

\section{Cloud computing and graphic design}

The graphic design industry has benefited mostly from programs like Adobe creative suite and other technological innovations like online storage and sharing of files (Holly, 2012). Graphic designers put in a lot of effort into creating engaging, quality work but this can result in large files that can be very difficult to handle. Using emails for such large files and complex work might face challenges as emails have limits in the amount of storage space allocated for each email address. With new advances in technologies, designers can now use cloud computing which allows them to store their work online and this enables them to not only deal with much larger files but also share these files easily with anyone that has internet connection. Cloud-based design applications offer more processing resources over several shared servers in a cloud-computing environment (Zorzini, 2012). Basically, this means that the graphic designer can use powerful design applications seamlessly on the Web. In the emerging markets context, the focus then becomes more directed at the designers' capability to access the internet, as a key factor in harnessing such services easily. Cloud computing allows companies to access software applications without suffering overhead costs in acquiring the software license fees (Kokubun, 2010). The issue of costs related to software purchase and license fees is one of the major challenges addressed by cloud computing. Models such as Software as a Service (SaaS) allow users to purchase licenses for their chosen software on-demand and this provides a temporary license to the user for a certain period (Kokubun, 2010). To the graphic designer who needs to use a certain software application for their work, this can prove to be the best option in that they do not intend to keep a copy of the application for future jobs. Ultimately, this gives flexibility to the designer to make well informed choices in light of what works well with their design.

\section{Crowdsourcing in design}

Regardless of the adverse effects it has brought to design and creativity, crowdsourcing is gaining in popularity among clients the world over, especially in the wake of spirited efforts to seek the best design work. In the graphic design industry, design contests are done online and there are websites offering such, like design99 and crowdSPRING. Through various websites, designers are now able to upload their portfolios online for reference to prospective clients. As such, this breaks down the geographical and cost barriers between designers and clients. Traditionally, designers used to receive critiques and feedback through studio critique sessions, where they would present their work to peers and mentors who would in turn provide comments and suggestions (Yuan et al., 2016). Crowdsourcing has proved to be a readily available method for effective feedback which has led some researchers to explore crowdsourcing as a potential solution to design problems (Luther et al., 2015). As a designer, one therefore has to make sure they have produced high quality work in anticipation of rife competition spawned by a myriad of online design contests. This brings a new dimension to how graphic design as an industry is evolving as new software are being offered to the market, whilst more powerful hardware accessories are being developed. All these software and hardware advancements are an effort to make the graphic design industry better. Though crowdsourcing has its own benefits, some of the designs submitted on sites like 99designs and crowdSPRING can be made public, depending on project settings, which might, however, encourage designers to plagiarize one another (Heer \& Bostock, 2010).

\section{Methodology}

This study sought to uncover qualitative insights in exploring the role of technology in the graphic design industry from the perspective of the designer in the developing economy. The study is both descriptive and explorative in nature, as the researcher used selected graphic designers in Zimbabwe. As such, the study exploits a qualitative approach as it is pragmatic, interpretive and grounded in lived experiences of the graphic designers. The researcher purposively selected only a sample of 50 graphic designers (as a subset of graphic designers in Zimbabwe) to respond to the questionnaires. The people targeted as key informants were purposively selected from Harare, considering numerous graphic design companies located in the capital city. The questionnaire had open-ended questions to allow the key informants to give full and meaningful responses. According to Reja et al. (2003), open-ended questions help in yielding the responses that respondents give spontaneously and thus avoid bias which might ordinarily occur in close-ended questions. Semi-structured, in-depth interviews were utilized for the 8 interviewees selected from the participants of a workshop that was carried in the capital on graphic design. These interviewees cited their availability, and thus made it much easier for the planned interviews to be carried out without problems. Rubin \& Rubin (2005) say that semi- structured interviews are more flexible as they allow "depth to be achieved by providing the opportunity on the part of the interviewer to probe and expand the interviewee's responses". 


\section{Discussion}

\section{Questionnaire Distribution and Return Rate}

Of the fifty (50) questionnaires distributed to graphic designers, 42 questionnaires were returned, giving a response rate of $84 \%$, which is quite good. Of the 42 respondents, only 10 designers have been in the graphic design industry for more than 5 years. This also yields a rough idea of how graphic design has been expanding as a key area in the $21^{\text {st }}$ century. All of the respondents with more than five years experience are holders of a certificate in design. It is only recently, with the expansion of the Zimbabwean curriculum through spawning of more universities, that we have seen a rise in degrees around the areas of creative arts. Long back, the graphic design industry was made up of graduates from the polytechnics dotted around the country. Also, with the advancements in technology, we have seen the widespread use of computers in the lower levels of education in high schools thus assisting in also developing young talents at an early age. From the interviews with designers, two of them did mention the fact that they self-taught themselves on the use of CorelDraw through videos found on YouTube. As they mastered the software, they started getting many jobs as freelance designers, but one hurdle they did face was they could not do jobs for some big companies as they did not have good academic qualifications. This then forced them to enroll first for certificate in graphic design, leading them to later attain a degree in creative art.

\section{Popular graphic design software}

Most graphic designers did mention that they prefer Adobe Creative Suite because of its interface, pointing out that it does not compromise on colour management and quality. They also noted that Adobe Photoshop has the advantage of downloadable plug-ins including brushes and textures which can update regularly when they are available. On further probing on why designers prefer Adobe, one respondent had this to say;

"It was introduced to me by one of my first Design mentors in late 2009. And I have grown into it, lucky it is actually one of the industry leading software"

He further explained that he is currently using the March 2017 latest Adobe creative cloud, since all updates are online for subscribers and he is using a licensed version of the software. Most of the graphic designers prefer Adobe full suite though they cited that they use CorelDraw more ton vector illustrations as it is the most preferred during the teaching and learning period from various institutions they came from. As a result, designers end up using different types of software to do their work. On the other side one respondent did mention that he has not been able to purchase the latest Adobe product due to cost and as such, uses the freely cracked version of the software. He further explained that the new versions do not necessarily bring any new features helpful to his design works.

"My Company does not want to pay license for latest version because there are no other features of significant change that are not available on my software"

Graphic designers who responded to the questionnaire pointed out that the new software upgrades or versions do not always bring much benefit to them. They also cited reasons like unaffordable hardware upgrades which the software may require in the future, which may be financially out of reach to them. This forces designers then to keep using the older versions since they will be managing to do with that software version without any upgrades.

\section{Software piracy}

Forty percent of the respondents did cite that they have genuine keys for their licenses which they paid for. This leaves us with sixty percent using the pirated version of the software. One respondent who works as a freelancer also said;

"There is no reason to purchase an upgraded version when I can easily get bridged software from friends."

The respondent further explained that he has been in the field of graphic designing since 2010 but has never used licensed software. The main argument raised was that there is no significant difference between the licensed and the unlicensed software, as they can easily get cracked versions online. All one needs is the internet connection to connect to sites that promote open access to software, where people share keys and tips to go around software. Though the inception of technological tools such as computers, software and the Internet has made our lives easier, abuse of such tools has created serious drawbacks like software piracy, which is now a growing concern for several countries. According to Khadka (2015), cost is one of the key motivating aspects for those who engage or use pirated software. From the developing world context, one's ability to purchase the software is also affected by the price difference charged between developed economies and developing economies, thus promoting piracy. Those countries referred to as emerging or developing economies have higher rates of pirated software (Khadka, 2015) a finding also supported in this study as Zimbabwe is also a developing economy. In some cases, one might be keen to pay for the software but they do face challenges in making the payment online, as these differ from region to region depending with the country's banks. 


\section{Graphic design qualifications}

To a larger extent, the respondents have certificates in graphic design from the local colleges that are offering graphic design as a course. This is because it does not require much to complete a graphic design course for a certificate and the population of graphic designers with certificates increases rapidly. Also, the curriculum is designed in such a way that it is more of the passion that drives one to be a designer rather than what they have done academically. As observed in the study, some of the interview respondents actually had very good portfolios showing their work from the early days up to the most recent designs they had done, despite the fact that they had not attained any formal training. As an industry, the graphic design sector thrives on the individual brilliance and creativity and as long as one puts more time to their work, they can become the world's sought after designers. One can also self-teach following the videos on the internet and they can do this in the comfort of their homes, developing themselves into good and competent graphic designers.

\section{Challenges related to software usage in graphic design}

In this study, three major problems were cited by the graphic designers in Zimbabwe and these include problems emanating from crowdsourcing, cost of software and hardware.

Crowdsourcing- Most designers cited that for one to be relevant in this industry, they need to have access to the internet as this keeps them abreast with technological changes. Some highlighted that they depend mostly on stock images from the internet and also get inspirations of recent works through sharing of portfolios via the internet. Only 8 respondents mentioned that they have entered contests online though only one managed to cite one winning entry for a logo design. Respondents who have not entered online contests cited time limit, as the main reason for failure to participate, considering that the online contests are too short. One respondent actually mentioned that due to the monetary issues facing Zimbabwe as a nation, it is difficult to access the prize money, as this would take a long process if one does not have an internationally accepted method of fund transfer. This in a way demotivates the graphic designer from taking part in the contests as they might face challenges in claiming their prize money. Two respondents also mentioned that they once entered the online contests but lost in the particular instance, though they felt their idea was later taken by another designer outside Zimbabwe for some logo design. This foregrounds the dynamics of crowdsourcing and the public domain, with focus directed at how owners of contests manage their contests and treats the final winning and losing entries. Some websites offer a chance to remove the loosing entries so that only the winning entry is available for viewing, but in some cases all entries winning and losing are left available on the internet for other designers to either get ideas or copy the whole concept for another project.Locally, there are contests where participation is via the social media platforms and seventy six percent (76\%) of the respondents highlighted that they have taken part in these contests managed through whatsapp or face book. The main reason, as supported also by the interviewees, is that within these groups on social media, the participants now know each other through the professional networks they have established.

Software and hardware issues-From the interviews, the cost of purchasing software for a first timer was cited as one of the biggest problems graphic designers face. Through further probing, some alluded to the fact that most freelance designers share copies of the new softwares and the moment a new version is released, they have people whom they know will always get these new versions for free to share with their friends within the graphic design world. Some respondents did mention that they try to raise extra funds for personal use whilst in school or university by doing small graphic design jobs like designing flyers for church, wedding invitations, and birthday celebration invites. However, these small jobs do not come so often for these designers, which therefore make it hard for them to pay a monthly or yearly subscription service for a creative cloud or license acquisition. Some respondents also did mention that even if they had the money, paying for the license is yet another difficult process due to the macroeconomic challenges facing Zimbabwe as a nation. Some designers did point out that some new software versions put a requirement on the hardware minimum specifications, thereby forcing one to either upgrade their machine or buy a new one. Given that these designers operate on a tight budget and their profits are not so big per job, they fail to buy the latest complimentary hardware requirements. It was also mentioned that for some designers, it is the hardware they have that controls their decision on what software version to have. This implies that such designers are not controlled by the various versions or upgrades, as they believe they can still do the same job using the old version of the same software.

\section{Conclusion}

From the study, one can conclude that software and hardware are key issues in the field of graphic design as they play a major role in the industry's deliverables. Though designers face a number of challenges brought about by globalization, they have managed to keep themselves relevant in the economy. Adobe products seem to be popular among the graphic designers despite the fact that they use pirated license versions. Graphic designers need to be well read, and well as to acquire the necessary skill sets to adapt easily from one trend to another as technological advancements affect the 
customer expectations. As such, education is key to the graphic designer, given the apparent need to learn how to manage their clients' expectations and how to balance between their creativity and design brief. Due to experiential skills the designers have gained, the software upgrades are not that important to the designers as they can easily do the jobs using the current or old versions well. Having a MAC or PC is not a determinant on the outcome of the product as both can do the same job without any distinction. The ease of access to the internet has a huge impact in the field of graphic design as new design ideas are shared easily across geographical boundaries. For one to make it in this industry, they must have a very good computer to handle the graphics involved. Equally needful are the requisite software, raw talent, education and dedication towards one's work.

\section{References}

Armitage, J. (2012) A Brief History of Graphic Design Part 1. Available from: http://d5media.co.uk/graphic-design/history-graphic-design/ [Accessed 1st March 2017].

Fiandaca, D. \& Burgoyne, P. (2010) Digital Advertising: Past, Present, and Future. UK, Creative Social.

Evans, L. (2014) Why Muse is the best web design tool we never had. Creative Bloq. Weblog. Available from: http://www.creativebloq.com/web-design/musetool-never-had-51411829 [Accessed 8 May 2017].

Gere, C. (2008) Digital Culture. 2nd ed. London, Reaktion Books.

Heer, J. \& Bostock, M. (2010) Crowdsourcing graphical perception: using mechanical turk to assess visualization design. In: 28th Annual CHI Conference on Human Factors in Computing Systems. Proceedings of the SIGCHI Conference on Human Factors in Computing Systems, CHI 2010, 10-15 April 2010, Atlanta, United States. New York, ACM. pp. 203-212. Available from: doi: 10.1145/1753326.1753357 [Accessed 2nd March 2017]

Hollis, R. (2002) Graphic Design: A Concise History. 2nd ed. New York, Thames and Hudson.

Khadka, I. (2015) Software piracy: A study of causes, effects and preventive measures. Undergraduate. Helsinki, Helsinki Metropolia University of Applied Sciences. Available from: https://www.theseus.fi/ bitstream/handle/10024/87274/Khadka_Ishwor. pdf? sequence $=1$ [Accessed 2nd March 2017].

Kokubun, R. (2010) Forecasting Cloud Computing for the Print Industry. BSc thesis. San Luis Obispo, California Polytechnic State University. Luther, K., Tolentino, J.L., Wu, W., Pavel, A., Bailey, B.P., Agrawala, M., Hartmann, B. \& Dow, S.P. (2015) Structuring, aggregating, and evaluating crowdsourced design critique. In: CSCW 2015. Proceedings of the 18th ACM Conference on Computer Supported Cooperative Work \& Social Computing, CSCW
2015, 14-18 March 2015, VancouverBC, Canada. New York, ACM. pp. 473-485. Available from: doi: 10.1145/2675133.2675283 [Accessed 3rd March 2017].

Meggs, P.B. (1998) A History of Graphic

Design. 3rd ed. New York, Wiley.

Perez, W. P. (2010) Graphic design before the computer, graphic design before the computer. Breezycreativedesign. Weblog. Available from: http://breezycreativedesign.com/2010/09/27/graphic-design-before-the-computer/ [Accessed 18th January 2017].

Reja, U., Manfreda, K. L, Hlebec, V. \& Vehovar, V. (2003) Open-ended vs. close-ended questions in web questionnaires. Developments in applied statistics. 19 (1), 159-177. Available from: https://www.stat-d. si/mz/mz19/reja.pdf [Accessed 19th January 2017].

Rubin, H. J. \& Rubin, I. S. (2005) Qualitative Interviewing - The Art of Hearing Data. 2nd ed. Thousand Oaks, Sage Publications. Available from: doi: 10.4135/9781452226651 [Accessed 19th January 2017].

Swedin, E. G. \& Ferro, D. L. (2005) Computers: The Life Story of a Technology. London, Greenwood Press.

Thornton, R. S. (1996) Graphic Design in a Box. National Forum, 76 (2). Available from: https:// www.highbeam.com/doc/1G1-18608363. html [Accessed 25th January 2017].

Yuan, A., Luther, K., Krause, M., Vennix, S., Dow, S. P. \& Hartmann, B. (2016) Almost an expert: The effects of rubrics and expertise on perceived value of crowd sourced design critiques. In: The 19th ACM conference on Computer-Supported Cooperative Work and Social Computing. Proceedings of the 19th ACM Conference on Computer-Supported Cooperative Work \& Social Computing, CSCW 2016, 26th February-2nd March, San Francisco, United States. New York, ACM. pp. 1005-1017. Available from: doi: 10.1145/2818048.2819953 [Accessed 2nd March 2017].

Zorzini, C. (22 May 2012) Tablets and the Future of Graphic Design. Inspired Magazine. Available from: http://inspiredm.com/tablets-and-the-future-ofgraphic-design/ [Accessed 11th March 2017]. 


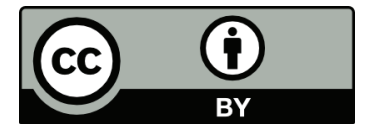

(C) 2018 Authors. Published by the University of Novi Sad, Faculty of Technical Sciences, Department of Graphic Engineering and Design. This article is an open access article distributed under the terms and conditions of the Creative Commons Attribution license 3.0 Serbia (http://creativecommons.org/licenses/by/3.0/rs/). 